\title{
Detecção de anticorpo anticoração em camundongos Balb/c imunizados com Streptococcus mutans
}

\section{Detection of heart-reactive antibody in Balb/c mice immunized with Streptococcus mutans}

\author{
Mariella Vieira Pereira LEÃO* \\ Adriana Aigotti Haberbeck BRANDÃO** \\ Elisabete MORAES** \\ Mário Tsunezi SHIMIZU*** \\ Carmelinda Schimidt UNTERKIRCHER****
}

\begin{abstract}
LEÃO, M. V. P.; BRANDÃO, A. A. H.; MORAES, E.; SHIMIZU, M. T.; UNTERKIRCHER, C. S. Detecção de anticorpo anticoração em camundongos Balb/c imunizados com Streptococcus mutans. Pesqui Odontol Bras, v. 14, n. 4, p. 319-326, out./dez. 2000.
\end{abstract}

\begin{abstract}
Anticorpos para antígenos cardíacos foram analisados por ELISA em 14 soros de camundongos Balb/c hiperimunizados com Streptococcus mutans, inativado pelo formaldeído. Os níveis de anticorpos da classe IgG anticoração e antimiosina elevaram-se significativamente nos animais imunizados quando comparados com os controles, especialmente no grupo A, imunizado e reestimulado com antígenos solúveis de S. mutans. Neste grupo, os resultados do "Western Blot" mostraram reatividade com miosina cardiaca e uma banda de $35 \mathrm{kDa}$. A análise histológica dos corações dos animais do grupo B, imunizado e reestimulado com antígenos de superficie do microrganismo, demonstrou a presença de degeneração celular, tipo hidrópica e hialina e focos inflamatórios constituídos de linfócitos e macrófagos no miocárdio e pericárdio. Os resultados deste trabalho reforçam a hipótese da existência de mimetismo antigênico entre tecido cardíaco e S. mutans e chamam a atenção para o risco de desenvolvimento de anticorpos reativos com antígenos próprios induzidos por vacina anticárie com componentes estreptocócicos.
\end{abstract}

UNITERMOS: Miocardite; Streptococcus mutans; Mimetismo molecular; Anticorpo anticoração; Anticorpo antimiosina.

\section{INTRODUÇÃO}

Ainda pouco se sabe a respeito da etiologia das doenças auto-imunes. Entre os diferentes fatores desencadeantes desse processo, o mimetismo antigênico e a modificação de antígenos próprios são os mais investigados ${ }^{15}$.

O mimetismo antigênico tem sido estudado na febre reumática, que representa a principal causa de morbidade e mortalidade cardiovascular em indivíduos de cinco a 24 anos nos países em desenvolvimento ${ }^{2}$. Esta doença geralmente desenvolve-se em indivíduos geneticamente suscetiveis, depois de infecções orofaringeas causadas por estreptococos $\beta$-hemolíticos do grupo A que têm reação cruzada com tecidos de mamíferos ${ }^{5,6}$.

Streptococcus mutans é um dos principais microrganismos cariogênicos que colonizam a super- fície dos dentes ${ }^{9}$. A imunização com antígenos purificados deste microrganismo induz proteção contra cárie dentária em diferentes modelos animais ${ }^{12}$. Entretanto, o principal obstáculo para o desenvolvimento de uma vacina anticárie foi o encontro de reatividade cruzada entre soros de coelhos hiperimunizados com $S$. mutans e tecido cardíaco huma$\mathrm{no}^{22}$.

A natureza e a identidade do antígeno de $S . m u$ tans envolvido na indução de anticorpos reativos com o tecido cardíaco ainda não é conhecida. Estudos com o antígeno I/II, principal antígeno da superficie celular do microrganismo, não confirmaram as suspeitas iniciais de reatividade cruza$\mathrm{da}^{18,23}$. Também não se sabe se estes anticorpos teriam algum papel na patogênese da miocardite induzida e iniciada, em animais de laboratório, por células T CD4 ${ }^{+11,19}$.

\footnotetext{
* Professora da Universidade do Vale do Paraíba, Mestranda da Faculdade de Odontologia de São José dos Campos da UNESP.

** Professoras Doutoras; **** Professora Adjunta - Faculdade de Odontologia de São José dos Campos da UNESP.

*** Professor Titular da Faculdade de Ciências Farmacêuticas da Universidade São Francisco.
} 
LEÃO, M. V. P.; BRANDÃO, A. A. H.; MORAES, E.; SHIMIZU, M. T.; UNTERKIRCHER, C. S. Detecção de anticorpo anticoração em camundongos Balb/c imunizados com Streptococcus mutans. Pesqui Odontol Bras, v. 14, n. 4, p. 319-326, out./dez. 2000.

Segundo ROSE et al. ${ }^{17}$ (1991), o grau de inflamação do miocárdio não se correlaciona muito bem com as alterações de função cardíaca, sugerindo um papel para os auto-anticorpos neste processo. Anticorpos reativos com o $\beta$-adrenorreceptor, com acetilcolinesterase e com o translocador de adenina nucleotídeo já foram descritos em pacientes com cardiopatia ${ }^{14,17}$.

A proposição do presente trabalho foi hiperimunizar camundongos Balb/c com antígenos de $S$. mutans e detectar a presença de anticorpos anticoração no soro e alterações histológicas no tecido cardiaco, a fim de verificar o risco da utilização de vacinas com componentes deste microrganismo.

\section{MATERIAIS E MÉTODOS Obtenção do antígeno}

1. extrato de coração: foram sacrificados vinte camundongos Balb/c e removidos os corações. O material foi lavado com solução salina tamponada fosfatada (PBS), para remoção do sangue. Posteriormente, os corações foram macerados com bastão de vidro em $10 \mathrm{ml}$ de PBS contendo fluoreto de fenilmetil sulfonil (PMSF) na concentração final de $5 \mathrm{mM}$, e filtrados em gaze esterilizada acondicionada num filtro de vidro. O filtrado obtido foi centrifugado a $5.000 \mathrm{rpm}$, por 10 minutos a $4^{\circ} \mathrm{C}$, e conservado a $-20^{\circ} \mathrm{C}$. Ao sedimento retido na gaze foram adicionados $5 \mathrm{ml}$ do tampão Tris- $\mathrm{HCl} 150 \mathrm{mM}$, uréia $6 \mathrm{M}, \beta$-mercaptoetanol $20 \mathrm{mM}$ e Tween-20 1\%. A mistura foi fervida por cinco minutos e mantida em geladeira, por 24 horas. Passado este período, o material foi centrifugado a $5.000 \mathrm{rpm}$, por $10 \mathrm{mi}-$ nutos a $4^{\circ} \mathrm{C}$, e o sobrenadante dialisado contra PBS, por toda noite. O filtrado conservado e o dialisado foram então misturados e concentrados por ultrafiltração em membrana P10 (Amicon), por 8 horas, a $4^{\circ} \mathrm{C}$, sob pressão de nitrogênio $75 \mathrm{psi}\left(5,3 \mathrm{~kg} / \mathrm{cm}^{2}\right)$. A concentração de proteínas foi estimada em $30 \mu \mathrm{g} / \mu \mathrm{l}$ pela técnica descrita em $1976^{3}$;

2. Streptococcus mutans: a bactéria, cepa CCT 1910, foi cultivada em $2.000 \mathrm{ml}$ de Triptic Soy Broth - TSB - (Difco), distribuído em três frascos Erlenmeyer, a $37^{\circ} \mathrm{C}$, por 24 horas, em atmosfera com $5 \%$ de $\mathrm{CO}_{2}$. O crescimento foi interrompido com formaldeído $0,075 \%$ e a cultura, deixada por 18 horas a $4^{\circ} \mathrm{C}$. A seguir, as células foram obtidas por centrifugação, lavadas três vezes em Tris- $\mathrm{HCl} 125 \mathrm{mM}$, EDTA $10 \mathrm{mM}$, $\mathrm{pH} 7,5$, e em seguida suspensas em $50 \mathrm{ml}$ do mesmo tampão, acrescentando-se PMSF na concentração final de $5 \mathrm{mM}$. A esta suspensão, adicionaram-se pérolas de vidro e agitou-se, a $50 \mathrm{rpm}$ em agitador (Etica-SP), por toda noite, a $4^{\circ} \mathrm{C}$. O lisado foi centrifugado a $7.000 \mathrm{rpm}$ por 30 minutos, a $4^{\circ} \mathrm{C}$, e o sobrenadante e o precipitado conservados. O sobrenadante foi dialisado contra Tris-HCl $125 \mathrm{mM}$, EDTA $10 \mathrm{mM}$, pH 7,5, concentrado e liofilizado, passando a constituir o antígeno citoplasmático. O precipitado foi adicionado de $5 \mathrm{ml}$ de Tris-HCl $150 \mathrm{mM}$, uréia $6 \mathrm{M}$, Tween-20 1\%, $\beta$-mercaptoetanol $20 \mathrm{mM}$, fervido por 5 minutos e conservado a $4^{\circ} \mathrm{C}$, por 24 horas. Após este período, foi centrifugado e o sobrenadante dialisado exaustivamente contra PBS, concentrado, liofilizado e conservado a $-20^{\circ} \mathrm{C}$, passando a constituir o antígeno de superficie. O conteúdo protéico foi determinado pelo método de BRADFORD ${ }^{3}$ (1976);

3. miosina de músculo cardiaco de porco (Sigma) e miosina de músculo esquelético de camundongo (6 $\mathrm{mg} / \mathrm{ml}$ ), doada pela Dra. Thérese Ternynck, do Instituto Pasteur de Paris;

4. anti-IgG1, 2 , 2 b e 3 (Sigma), para a detecção de subclasses de IgG.

\section{Imunização}

Camundongos Balb/c, de seis semanas de idade, foram divididos em dois grupos. Os camundongos do grupo A $(\mathrm{n}=8)$ foram imunizados, por via intraperitoneal, com $100 \mu 1$ de uma suspensão contendo $3,4 \times 10^{6}$ células de $S$. mutans, cepa CCT 1910, mortas pela adição de formaldeído a $0,075 \%$, emulsificada em $100 \mu 1$ de adjuvante de Freund incompleto (Sigma). Foram administradas duas injeções, com intervalos de três semanas. A seguir, administraram-se mais quatro injeções, pela mesma via, com intervalos de uma semana, com $100 \mu 1$ da suspensão em $100 \mu 1$ de sulfato de alumínio e potássio. Depois de dois meses de imunização e um intervalo de quatro semanas, os animais foram reestimulados ("booster") com $300 \mu \mathrm{g}$ do antígeno citoplasmático de S. mutans, obtido pelo método descrito anteriormente, em solução salina isotônica esterilizada. Uma semana após a reestimulação, os animais foram anestesiados e o sangue, colhido por via retro-ocular para a análise sorológica.

O grupo $B(n=6)$ foi imunizado seguindo o mesmo protocolo, porém, um mês após o "booster", os animais receberam uma nova reestimulação com $300 \mu \mathrm{g}$ do antígeno de superfície do estreptococo 
LEÃO, M. V. P.; BRANDÃO, A. A. H.; MORAES, E.; SHIMIZU, M. T.; UNTERKIRCHER, C. S. Detecção de anticorpo anticoração em camundongos Balb/c imunizados com Streptococcus mutans. Pesqui Odontol Bras, v. 14, n. 4, p. 319-326, out./dez. 2000.

em solução salina isotônica esterilizada. Uma semana após a reestimulação, os animais foram anestesiados e o sangue, colhido por via retro-ocular para a análise sorológica.

Depois de sangrados, os camundongos foram sacrificados e os corações, removidos para a análise histológica.

O grupo controle $(n=5)$ não foi imunizado com S. mutans, apenas recebeu os adjuvantes de acordo com o mesmo protocolo dos grupos experimentais.

\section{Análise dos anticorpos}

\section{ELISA}

As placas de poliestireno (Costar) foram sensibilizadas com $50 \mu 1$, por orificio, de extrato de coração $(100 \mu \mathrm{g} / \mathrm{ml})$, antígenos citoplasmáticos de $S$. mutans $(100 \mu \mathrm{g} / \mathrm{ml})$ ou miosina $(5 \mu \mathrm{g} / \mathrm{ml})$, em tampão carbonato-bicarbonato $0,1 \mathrm{M}, \mathrm{pH} 9,6$, por 2 horas, a $37^{\circ} \mathrm{C}$. Depois disso, os sítios não ocupados foram saturados com $0,5 \%$ de gelatina (Gibco) em PBS, por trinta minutos, a $37^{\circ} \mathrm{C}$, e lavados com PBS, contendo 0,1\% de Tween-20 (PBS-T). Posteriormente, adicionaram-se, em cada orificio da primeira linha, $100 \mu \mathrm{l}$ de soro dos camundongos diluído a 1/25 em PBS-T-gelatina (PBS-T-G). Nas linhas seguintes, foram feitas diluições consecutivas, na razão dois ( $50 \mu 1$ /orifício). Então, as placas foram incubadas a $37^{\circ} \mathrm{C}$, por duas horas, e a $4^{\circ} \mathrm{C}$, por toda noite. No dia seguinte, as placas foram lavadas com PBS-T e, posteriormente, foram adicionados aos orificios $50 \mu 1$ do conjugado anti-IgG marcado com peroxidase (Sigma), numa concentração de $1 \mu \mathrm{g} / \mathrm{ml}$. A atividade de peroxidase foi revelada utilizando-se ortofenilenodiamino (Sigma): $6 \mathrm{mg}$ em $12 \mathrm{ml}$ de tampão citrato-ácido cítrico $0,1 \mathrm{M}, \mathrm{pH} 5,5$ e $10 \mu \mathrm{lde} \mathrm{H}_{2} \mathrm{O}_{2}$ a $30 \%, 100 \mu 1$ por orifício. A reação foi bloqueada com $50 \mu \mathrm{l}$ de ácido sulfúrico 2,5 normal $(\mathrm{N})$. As densidades ópticas (DO) foram lidas a $490 \mathrm{~nm}$.

$\mathrm{Na}$ análise de subclasses, foram utilizados anticorpos de coelho especificos para cada subclasse de IgG (anti-IgG1, 2 $2,2_{b}$ ou 3 ) de camundongo e conjugado anti-IgG de coelho marcado com peroxidase (1/3.000). Na revelação, utilizaram-se nove partes de uma solução de sulfanato de 2'-2'-azino-di (3-etil-benziltiazolina) e uma parte de uma solução peróxido de hidrogênio (Peroxidase Substrate Kit - Biorad). A reação foi interrompida com ácido oxálico a $2 \%$ e a leitura da DO, realizada a $415 \mathrm{~nm}$.

\section{Eletroforese em gel de poliacrilamida e "Wes- tern Blot"}

A técnica de "Western Blot" foi desenvolvida de acordo com TOWBIN et al. ${ }^{21}$ (1979). Após a eletroforese em gel de poliacrilamida, obteve-se a réplica do gel em membrana de nitrocelulose (Amersham). Foi aplicado no gel $30 \mu \mathrm{g}$ de antígeno de coração, $20 \mu \mathrm{g}$ de antígeno de $S$. mutans ou $5 \mu \mathrm{g}$ de miosina, por "slot".

Os sitios livres da nitrocelulose foram saturados com PBS-T contendo 5\% de leite desnatado (Molico - Nestlé), por duas horas, sob agitação. Em seguida, foi feita a incubação, por uma noite à temperatura ambiente, sob agitação, com o soro dos camundongos, diluído a 1/50 no mesmo tampão. No dia seguinte, a nitrocelulose foi lavada com PBS-T, e depois, incubada com conjugado anti-IgG de camundongo, marcado com peroxidase (duas horas à temperatura ambiente, sob agitação). Após este periodo, as fitas foram novamente lavadas com PBS-T e, então, incubadas com substrato diaminobenzidina (Sigma) a 0,01\%, em 0,1 M de Tris- $\mathrm{HCl}, \mathrm{pH} 7,5$ e $0,003 \%$ de $\mathrm{H}_{2} \mathrm{O}_{2}$. A reação foi interrompida com água destilada.

\section{Análise histológica}

Os corações foram retirados e imediatamente colocados no fixador (formol a 10\%). Depois de fixadas, as peças foram hemi-seccionadas e incluídas em parafina. Cortes de $5 \mu \mathrm{m}$ foram realizados em micrótomos convencionais e corados pela técnica de hematoxilina-eosina. Nos diferentes cortes, pesquisaram-se focos de inflamação no miocárdio e nas válvulas cardíacas.

\section{Análise estatística}

Os dados obtidos foram analisados pelo teste $t$ de Student.

\section{RESULTADOS Detecção de anticorpos por ELISA}

A imunização dos camundongos com antígenos estreptocócicos induziu uma forte resposta de anticorpos específicos nos dois grupos estudados (dados não mostrados).

Os Gráficos 1 e 2 mostram a reatividade dos anticorpos da classe IgG para antígenos cardíacos e miosina presentes nos soros dos animais do grupo A. Pode-se observar que a imunização também induziu a sintese de anticorpos capazes de reconhecer estes antígenos. Os gráficos mostram diferenças significativas nos títulos de anticorpos IgG 
LEÃO, M. V. P.; BRANDÃO, A. A. H.; MORAES, E.; SHIMIZU, M. T.; UNTERKIRCHER, C. S. Detecção de anticorpo anticoração em camundongos Balb/c imunizados com Streptococcus mutans. Pesqui Odontol Bras, v. 14, n. 4, p. 319-326, out./dez. 2000.

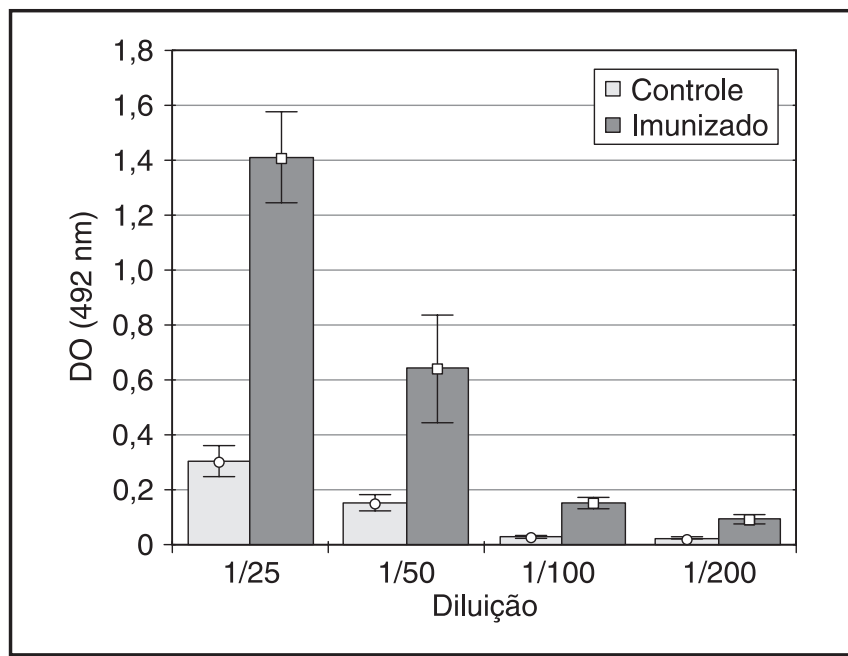

GRÁFICO 1 - ELISA - Reatividade média de IgG sérica anticoração em animais imunizados do grupo $\mathrm{A}$ e não-imunizados.

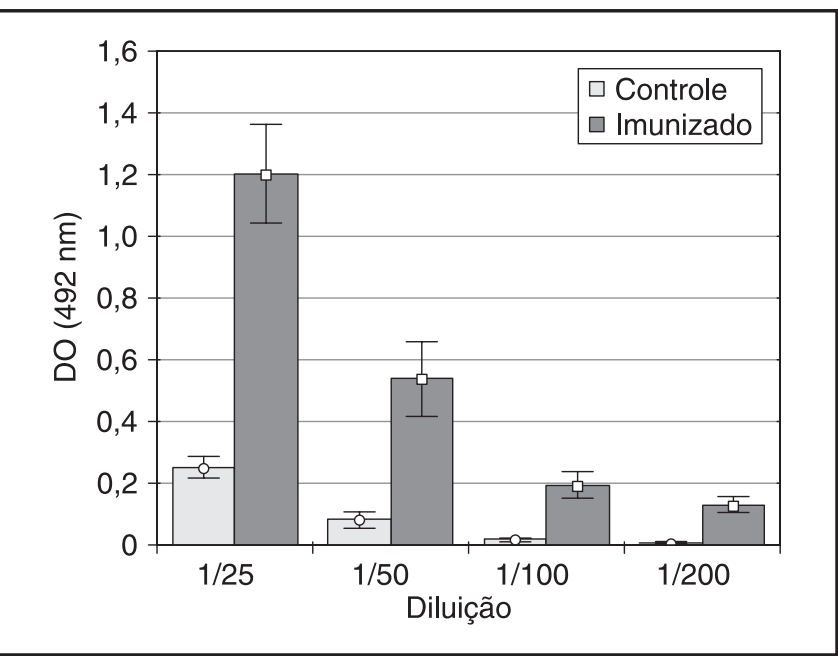

GRÁFICO 2 - ELISA - Reatividade média de IgG sérica antimiosina em animais imunizados do grupo A e não-imunizados.

anticoração e antimiosina entre os animais imunizados e não-imunizados. Estas diferenças mostram-se significantes nas quatro diluições testadas $(\mathrm{p}<0,05)$.

A reatividade média dos anticorpos da classe IgG anticoração e antimiosina presentes nos soros dos animais do grupo B não foi tão evidente quanto a observada no primeiro grupo estudado, embora tenha sido superior aos animais controle (dados não mostrados).

Os resultados obtidos na identificação das subclasses de IgG anti-S. mutans, realizada apenas no grupo B, são apresentados no Gráfico 3. Verifi-

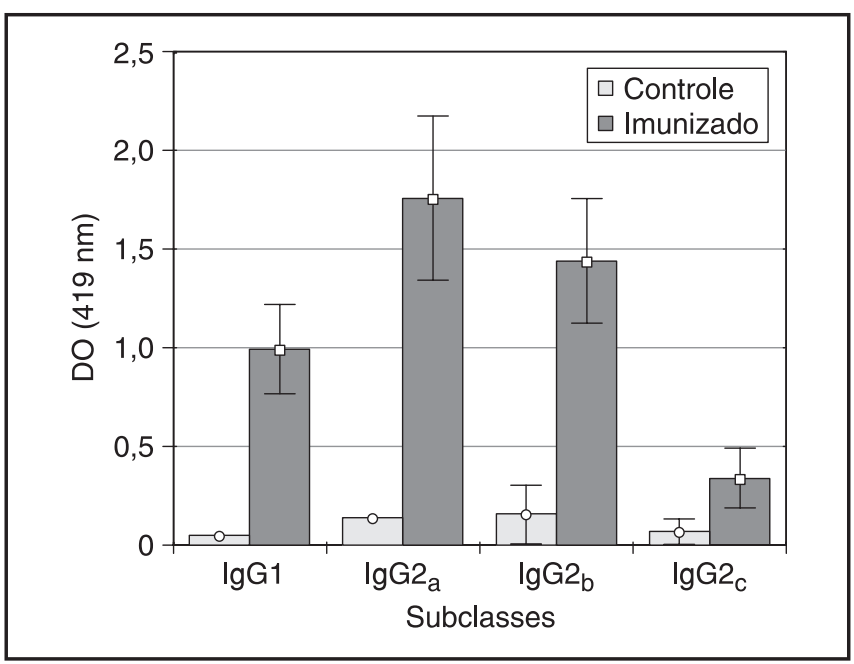

GRÁFICO 3 - ELISA - Reatividade média de IgG sérica anti-S. mutans de diferentes subclasses em animais imunizados do grupo B e não-imunizados.

cou-se que as mais representativas foram IgG2 $2_{\mathrm{a}} \mathrm{e}$ IgG2 $2_{\mathrm{b}}$. Já os niveis de IgG1 e IgG3 eram mais baixos nos soros dos animais imunizados. Quanto às cadeias leves $\kappa$ e $\lambda$ das IgGs, a cadeia $\kappa$ foi sempre a mais representada (dados não mostrados).

\section{Detecção de anticorpos pelo "Western Blot"}

Os anticorpos da classe IgG do soro de animais não-imunizados reconheceram polipeptídeos de pesos moleculares aproximados de $51 \mathrm{kDa}$ e $78 \mathrm{kDa}$, na preparação de S. mutans, enquanto os antígenos do coração não foram reconhecidos. Os animais imunizados, do grupo A, reconheceram outras bandas na preparação bacteriana com pesos moleculares de 26 e $94 \mathrm{kDa}$, entre outras. No extrato de coração, esses anticorpos reagiram com um componente de peso molecular $35 \mathrm{kDa}$ (Figura 1). A reatividade das IgGs dos mesmos animais para miosina cardiaca também pôde ser observada (Figura 2). Já os soros dos animais imunizados do grupo B não foram capazes de reconhecer qualquer fração antigênica no extrato de coração, embora a reatividade para $S$. mutans estivesse bastante evidente (dados não mostrados).

\section{Análise histológica}

Nos cortes histológicos dos animais imunizados do grupo A, observaram-se alterações muito discretas no tecido cardiaco. No miocárdio e no pericárdio, encontraram-se pequenos focos de inflamação, constituídos principalmente por linfócitos, além de algumas fibras miocárdicas de coloração mais eosinofilica, causada por degeneração tipo 
LEÃO, M. V. P.; BRANDÃO, A. A. H.; MORAES, E.; SHIMIZU, M. T.; UNTERKIRCHER, C. S. Detecção de anticorpo anticoração em camundongos Balb/c imunizados com Streptococcus mutans. Pesqui Odontol Bras, v. 14, n. 4, p. 319-326, out./dez. 2000.

hialina (dados não mostrados). Já os animais do grupo B apresentaram alterações mais significativas. Observou-se, no pericárdio e no miocárdio, infiltrado inflamatório moderado ou acentuado, constituído de linfócitos e macrófagos, especialmente nas regiões perivasculares do pericárdio, associado a edema e congestão. Também pôde-se notar a presença de maior quantidade de fibras cardiacas irregulares, com citoplasma intensamente eosinofilico devido à degeneração tipo hialina, além de fibras com degeneração hidrópica, representada por vacúolos citoplasmáticos (Figura 3).

\section{DISCUSSÃO}

No presente trabalho, examinou-se o nivel de anticorpos reativos com antígenos do coração, em camundongos Balb/c hiperimunizados com Streptococcus mutans. Analisando-se os resultados obtidos por ELISA, verificou-se que a elevação dos anticorpos específicos para $S$. mutans foi acompanhada de um aumento de reatividade para antígenos do coração e miosina. Estes resultados estão de acordo com relatos anteriores sobre a presença de anticorpos antimiocárdio em animais hiperimunizados com este microrganismo $\mathrm{o}^{4,8,22}$.
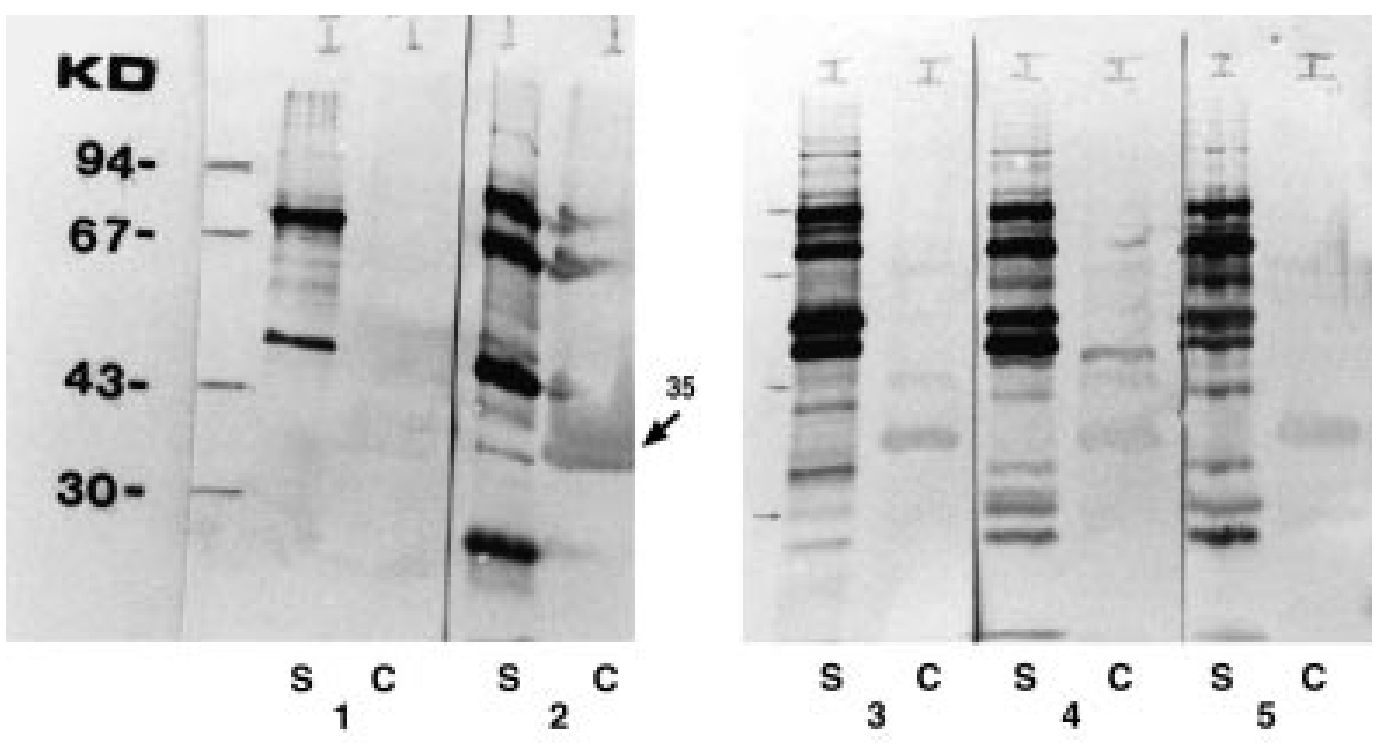

FIGURA 1 - "Western Blot"- Reatividade dos anticorpos da classe IgG presentes nos soros dos animais imunizados do grupo A e não-imunizados. 1 - soro controle, 2 a 5 - soros de animais imunizados. S antigeno de $S$. mutans, C - antígenos cardiacos.
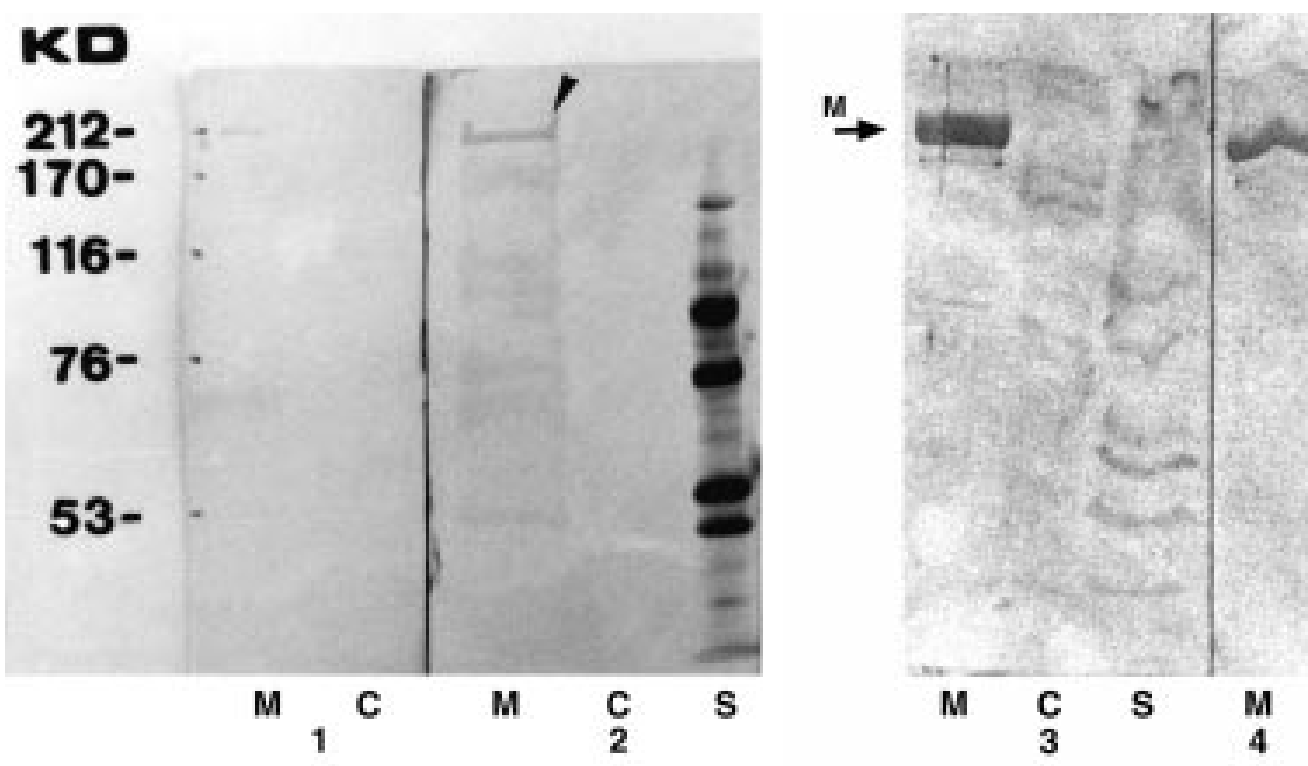

FIGURA 2 - "Western Blot"Reatividade das IgGs séricas dos animais imunizados do grupo A, para antígenos estreptocócicos, cardíacos e miosina cardíaca. 1 - soro controle, 2 a 4 - soros de animais imunizados.

$\mathrm{S}$ - antígenos de S. mutans, C - antígenos cardiacos, M - miosina cardíaca. 
LEÃO, M. V. P.; BRANDÃO, A. A. H.; MORAES, E.; SHIMIZU, M. T.; UNTERKIRCHER, C. S. Detecção de anticorpo anticoração em camundongos Balb/c imunizados com Streptococcus mutans. Pesqui Odontol Bras, v. 14, n. 4, p. 319-326, out./dez. 2000.
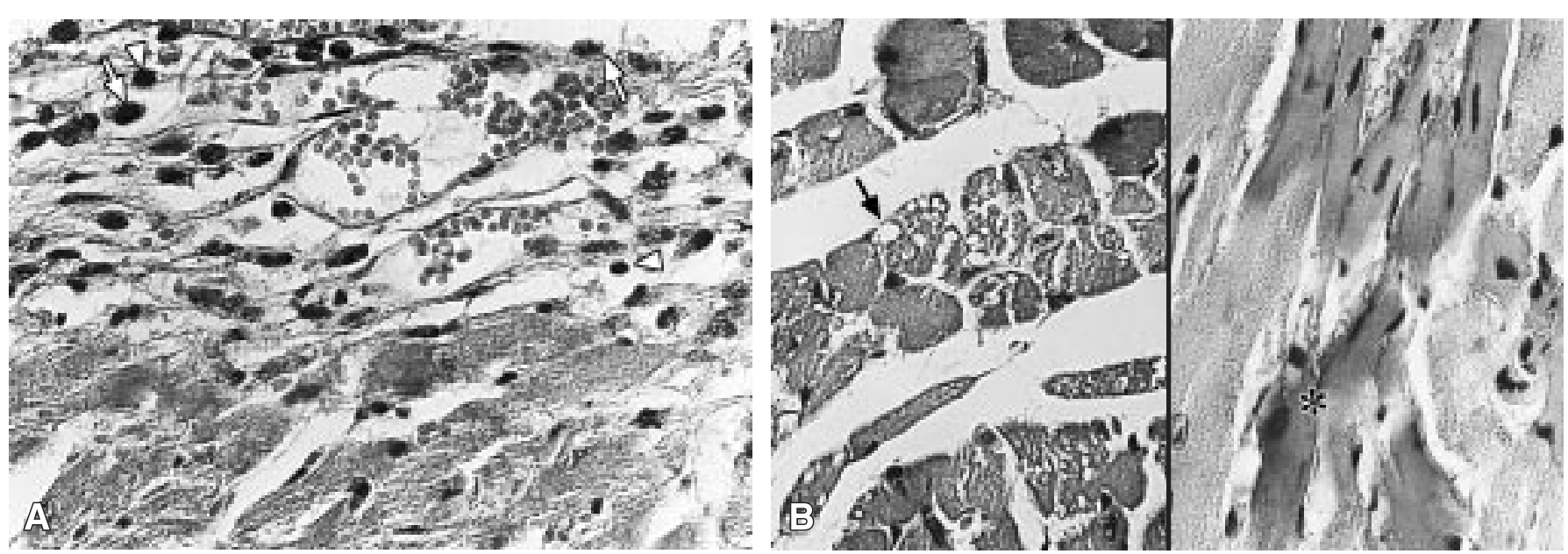

FIGURA 3 - Cortes histológicos do coração de camundongo do grupo B: (A) pericárdio com infiltrado inflamatório - macrófagos (setas longas) e linfócitos (setas curtas) (H. E., 630 X); (B) fibras cardíacas com degeneração hidrópica (seta) e hialina (asterisco) (H. E., $630 \mathrm{X}$ ).

Baixos níveis de anticorpos reativos com antígenos próprios foram encontrados em soros de indivíduos saudáveis, apresentando elevações transitórias e alterações de especificidade em diversas situações patológicas ${ }^{1,13}$. TERNYNCK et al. ${ }^{20}$ (1990) estudando camundongos infectados com Trypanosoma cruzi, observaram um aumento de anticorpos reativos com antígenos próprios que pertenciam principalmente à classe IgG, subclasses IgG2 a e IgG2 ${ }_{b}$. Neste estudo, verificou-se que os anticorpos aumentados nos soros dos camundongos imunizados também pertenciam a estas subclasses. Além disso, a maioria deles possuía cadeia leve $\kappa$, cuja prevalência em camundongos já é conheci$\mathrm{da}^{16}$.

Assim, um aumento temporário de anticorpos reativos com antígenos próprios após a imunização dos animais com antígenos bacterianos poderia ser considerado um fenômeno normal. Entretanto, clones de linfócitos B produzindo auto-anticorpos naturais poderiam, após mutação somática, originar outra população de imunoglobulinas com atividade patológica ${ }^{7}$.

LIAO et al. ${ }^{11}$ (1995) demonstraram que anticorpos antimiosina poderiam causar miocardite em animais suscetiveis. Camundongos da raça DBA/2 desenvolviam a patologia após administração de anticorpos monoclonais antimiosina, enquanto camundongos Balb/c não o faziam.

Neste experimento, utilizaram-se camundongos Balb/c, resistentes à indução de lesões cardíacas pelos auto-anticorpos. Na análise histológica, verificou-se que os animais do grupo A, cuja resposta humoral anticoração era mais evidente, sofreram pequenas alterações cardíacas. Já os animais do grupo B, apresentaram níveis menores de auto-anticorpos, mas desenvolveram lesões mais significativas. Isto significa que o nivel de anticorpos reativos com antígenos do coração não está necessariamente associado ao grau de lesão cardiaca, provavelmente causada por uma resposta do tipo Th1. Os animais do grupo B receberam na última semana de imunização uma injeção com antígenos de superficie de $S$. mutans (membrana e parede) e essa alteração no protocolo de imunização pode ter sido responsável pelo desvio da resposta imunológica para Th1 e, conseqüentemente, aumento da lesão no tecido cardíaco. É importante salientar que a resposta dos animais para os componentes de 26, 51, 78 e $94 \mathrm{kDa}$ de $S$. mutans não se alterou, permanecendo alta nos dois grupos.

$\mathrm{O}$ antígeno do tecido cardíaco reconhecido pelos soros de animais hiperimunizados era uma proteína de peso molecular $35 \mathrm{kDa}$. Achado que está de acordo com KHANNA et al. ${ }^{10}$ (1997) que observaram em soros de pacientes com febre reumática aguda reatividade com um polipeptídeo de $38 \mathrm{kDa}$ nas membranas de sarcolema de tecido cardiaco humano, reconhecido por anticorpos antitropomiosina cardiaca humana.

Os achados obtidos neste trabalho sugerem que a imunização com antígenos de S. mutans pode induzir um aumento de anticorpos reativos com antígenos do coração, principalmente com uma proteína de $35 \mathrm{kDa}$ e produzir alterações no tecido 
LEÃO, M. V. P.; BRANDÃO, A. A. H.; MORAES, E.; SHIMIZU, M. T.; UNTERKIRCHER, C. S. Detecção de anticorpo anticoração em camundongos Balb/c imunizados com Streptococcus mutans. Pesqui Odontol Bras, v. 14, n. 4, p. 319-326, out./dez. 2000.

cardíaco. Novos estudos devem ser realizados visando identificar o antígeno estreptocócico de reatividade cruzada.

\section{CONCLUSÕES}

A análise dos soros dos camundongos hiperimunizados com Streptococcus mutans demonstrou elevação dos niveis séricos de anticorpos reativos com extratos do coração e miosina cardíaca. Estes anticorpos eram principalmente da classe IgG, subclasses IgG2 $2_{\mathrm{a}}$ e IgG2 $2_{\mathrm{b}}$ e reconheciam uma proteína de peso molecular de $35 \mathrm{kDa}$ do antígeno do coração, possivelmente a tropomiosina.

Verificamos que a elevação sérica dos anticorpos anticoração e antimiosina não mostrou uma correlação com o grau de lesão tecidual, pois as maiores alterações teciduais foram encontradas em camundongos reestimulados com antígenos de superficie de S. mutans, que apresentaram menor resposta humoral para antígenos do coração.

LEÃO, M. V. P.; BRANDÃO, A. A. H.; MORAES, E.; SHIMIZU, M. T.; UNTERKIRCHER, C. S. Detection of heart-reactive antibody in Balb/c mice immunized with Streptococcus mutans. Pesqui Odontol Bras, v. 14, n. 4, p. 319-326, out./dez. 2000.

Heart-reactive antibodies were examined by ELISA, in sera from 14 Balb/c mice immunized with Streptococcus mutans inactivated by treatment with formaldehyde. Anti-heart and anti-myosin IgG levels increased significantly in the sera from immunized mice, when compared with those of control sera, especially in the first group, inoculated with a new antigen preparation. This group displayed a notable reactivity with cardiac myosin and cardiac tissue proteins in Western-blotting, mainly with a $35 \mathrm{kDa}$ peptide. The histological analysis of immunized animals' cardiac tissue demonstrated the existence of cell injury and eosinophilia attributable to cellular hyaline change. The pericardium and the myocardium showed inflammatory infiltrate formed by lymphocytes and macrophages. These findings suggest the existence of molecular mimicry between $S$. mutans and the cardiac tissue and emphasize the risk of development of an autoimmune myocarditis induced by caries vaccine containing streptococcal fractions.

UNITERMS: Myocarditis; Streptococcus mutans; Molecular mimicry; Anti-heart antibodies; Anti-myosin antibodies.

\section{REFERÊNCIAS BIBLIOGRÁFICAS}

1. BERNEMAN, A.; GUILBERT, B.; ESCHRICH, S. et al. IgG auto- and polyreactivities of normal human sera. Mol Immunol, v. 30, n. 16, p. 1499-1510, Nov. 1993.

2. BINO, A. L. Rheumatic fever. In: KELLEY, W. N. et al. Text book of rheumatology. 5. ed. Philadelphia : Saunders, 1997. p. 1225-1240.

3. BRADFORD, M. A rapid and sensitive method for the quantification of microgram quantities of protein utilizing the principle of protein-dye binding. Anal Biochem, v. 72, p. 248-254, May 1976.

4. FERRETTI, J. J.; SHEA, C.; HUMPHREY, M. W. Cross-reactivity of Streptococcus mutans antigens and human heart tissue. Infect Immun, v. 30, n. 1, p. 69-73, Oct. 1980.

5. GIBOFSKY, A.; ZABRISKIE, J. B. Rheumatic fever and poststreptococcal reactive arthritis. Curr Open Rheumatol, v. 7, n. 4, p. 299-305, June 1995.

6. GIBOFSKY, A.; KHANNA, A.; SUH, E. et al. The genetics of rheumatic fever: relationship to streptococcal infection and autoimmune disease. J Rheumatol, v. 30, p. 1-5, Aug. 1991. Supplement.

7. GILBERT, D.; MARGARITTE, C.; PAYELLE BROGART, B. et al. Development of the $\mathrm{B}$ cell anti-DNA repertoire in (NZB x NZW) F1 mice . Relationship with the natural autoimmune repertoire. J Immunol, v. 149, n. 5, p. 1795-1801, Sept. 1992.
8. HUGHES, M.; MACHARDY, S. M.; SHEPPARD, A. J. et al. Evidence for an immunological relationship between Streptococcus mutans and human cardiac tissue. Infect Immun, v. 27, n. 2, p. 576-588, Feb. 1980.

9. JORGE, A. O. C. Microbiologia da cárie dentária. In: JORGE, A. O. C. Microbiologia bucal. São Paulo : Santos, 1995. p. 50-65.

10. KHANNA, A. K.; NOMURA, Y.; FISCHETTI, V. A. et al. Antibodies in the sera of acute rheumatic fever patients bind to human cardiac tropomyosin. J Autoimmun, v. 10, n. 1, p. 99-106, Feb. 1997.

11. LIAO, L.; SINDHWANI, R.; ROJKIND, M. et al. Antibody-mediated autoimmune myocarditis depends on genetically determined target organ sensitivity. J Exp Med, v. 181, n. 3, p. 1123-1131, Mar. 1995.

12. MICHALEK, S. M.; CHILDERS, N. K. Development and outlook for a caries vaccine. Crit Rev Oral Biol, v. 1, n. 1, p. 37-54, 1990.

13. MIRILAS, P.; FESEL, C.; GUILBERT, B. et al. Natural antibodies in childhood: development, individual stability and injury effect indicate a contribution to immune memory. J Clin Immunol, v. 19, n. 2, p. 109-115, Mar. 1999.

14. OUASSI, M. A.; CORNETTE, J.; VELGE, P. et al. Identification of anti-acetylcholinesterase and anti-idiotype antibodies in human and experimental Chagas' disease: pathological implications. Eur J Immunol, v. 18, p. 1889-1894, 1988. 
LEÃO, M. V. P.; BRANDÃO, A. A. H.; MORAES, E.; SHIMIZU, M. T.; UNTERKIRCHER, C. S. Detecção de anticorpo anticoração em camundongos Balb/c imunizados com Streptococcus mutans. Pesqui Odontol Bras, v. 14, n. 4, p. 319-326, out./dez. 2000.

15. PETRY, K.; EISEN, H. Chagas' disease: a model for the study of autoimmune disease. Parasitol Today, v. 5, n. 4, p. 111-116, 1989.

16. ROITT, I. Autoimmunity and autoimmune disease. In: ROITT, I.; BROSTOFF, J.; MALE, D. Immunology. 5. ed. Londres : Mosby, 1998. p. 367-380.

17. ROSE, N. R.; NEUMANN, D. A.; HERSKOWITZ, A. Autoimmune myocarditis: concepts and questions. Immunol Today, v. 12, n. 8, p. 253-255, Aug. 1991.

18. RUSSELL, M. W.; WU, H. Y.; WHITE, P. L. et al. Serum antibody responses to Streptococcus mutans antigens in humans systemically infected with oral streptococci. Oral Microbiol Immunol, v. 7, n. 6, p. 321-325, Dec. 1992.

19. SMITH, S. C.; ALLEN, P. M. Myosin-induced acute myocarditis is a $\mathrm{T}$ cell-mediated disease. J Immunol, v. 147, n. 7 , p. 2141-2147, Oct. 1991.
20. TERNYNCK, T.; BLEUX, C.; GREGOIRE, J. et al. Comparison between autoantibodies arising during Trypanosoma cruzi infection in mice and natural antibodies. $\mathbf{J}$ Immunol, v. 144, n. 4, p. 1504-1511, Feb. 1990.

21. TOWBIN, H.; STAEHELIN, T.; GORDON, J. Eletrophoretic transfer of proteins from polyacrylamide gels to nitrocellulose sheets: procedure and some applications. Proc Natl Acad Sci, v. 76, n. 9, p. 4350-4354, Sept. 1979.

22. van de RIJN, I.; BLEIWEIS, A. S.; ZABRISKIE, J. B. Antigens in Streptococcus mutans cross reactive with human heart muscle. J Dent Res, v. 55, p. 59-64, Apr. 1976.

23. WU, H.; RUSSELL, M. W. Immunological cross-reactivity between Streptococcus mutans and human heart tissue examined by cross-immunization experiments. Infect Immun, v. 58, n. 11, p. 3545-3552, Nov. 1990.

Recebido para publicação em 10/02/00 Enviado para reformulação em 14/07/00 Aceito para publicação em 18/08/00 